\title{
Comparison of Hemodynamic, Emergence and Recov Ery Characteristics of Sevoflurane with Desflurane in General Anesthesia
}

\author{
Dr.Vairavarajanchandrasekaran, Dr. Lakshmi Sudha \\ Institute Of Anaesthesiology, Madurai Medical College, Madurai
}

\begin{abstract}
General anesthesia is a dynamic balance between the level of hypnosis, analgesia, and stimulation. It is usually defined as a triad of amnesia, analgesia, and muscle relaxation. Inhaled volatile anaesthetics remain the most widely used drugs for maintenance of general anesthesia because of their predictable intraoperative and recovery characteristics. Management of haemodynamic stability and early recovery is the most important part of a standardized balanced technique. The aim of this study is to prospectively compare the hemodynamic, emergence and recovery characteristics of sevoflurane with that of desflurane in general anesthesia. 60 ASA I and II patients undergoing elective surgical procedures less than 3 hours duration under endotracheal general anesthesia were randomly divided into two groups. Both the groups were induced with standard intravenous induction technique. Group D was maintained with $3 \%$ desflurane and group S with 1\% sevoflurane in 50\% oxygen with 50\% nitrous oxide. In conclusion, desflurane provides earlier emergence and recovery from anesthesia compared to sevoflurane. Both desflurane and sevoflurane maintained hemodynamic stability intraoperatively, but to maintain the hemodynamicsdesflurane needed more number of additional doses of fentanyl.
\end{abstract}

Keywords: desflurane, general anaesthesia, hemodynamics, sevoflurane

\section{Introduction}

The introduction of general anesthetics into clinical practice over 150 years ago stands as one of the seminal innovations of medicine. This single discovery facilitated the development of modern surgery and spawned the speciality of anaesthesiology.

General anesthesia can broadly be defined as a drug-induced reversible depression of the central nervous system resulting in the loss of response to and perception of all external stimuli. General anesthesia is a dynamic balance between the level of hypnosis, analgesia, and stimulation. It is usually defined as a triad of amnesia, analgesia, and muscle relaxation.

Inhalation anesthetics are the most common drugs used for the provision of general anesthesia. Adding only a fraction of a volatile anesthetic to the inspired oxygen results in a state of unconsciousness and amnesia. When combined with intravenous adjuvants, opioids and benzodiazepines, a balanced anesthetic technique is achieved that results in analgesia, further sedation or hypnosis, and amnesia. The popularity of the inhaled anesthetics for surgical procedures is because of their ease of administration and the ability to reliably monitor their effects with both clinical signs and end-tidal concentrations.

Inhaled volatile anaesthetics remain the most widely used drugs for maintenance of general anesthesia because of their predictable intraoperative and recovery characteristics. Management of haemodynamic stability and early recovery is the most important part of a standardized balanced technique.

Rapid induction and recovery may lead to faster operating room turnover times, shorter recovery room stays, and earlier discharges to home.

Over the last 15 years, there has been an explosive growth in the trend to provide cost-effective care in the practice of medicine. Ambulatory surgery is an increasingly important part of that trend. Ambulatory surgery continues to grow and thrive such that the vast majority (65-70\%) of all surgical procedures is performed on an outpatient basis. Expeditious recovery and shorter hospital stays are necessary to improve efficiency of an ambulatory facility and reduce health care costs. One of the major factors that determine the speed of recovery from anesthesia is the choice of anesthetic technique. Although local and regional anesthesia techniques are increasingly used in the ambulatory setting because they allow a more rapid recovery, general anesthesia is still the most common anesthetic technique. An ideal general anesthetic technique should provide smooth and rapid induction, optimal operating conditions, and rapid recovery with minimal or no side effects. It is also beneficial if the anesthetic technique allows for fast tracking (i.e, transferring patients directly from the operating room to the phase II unit, thus bypassing the postanesthesia care unit [PACU]).

Inhaled anaesthetics allow rapid emergence from anaesthesia because of easy titrability with inherent neuromuscular blocking effects that make them more suitable for ambulatory anaesthesia. The availability of 
less soluble inhalation anaesthetics such as sevoflurane and desflurane made us rethink about the selection of volatile anaesthetics for outpatient surgical procedures. Given the low blood: gas partition coefficient of sevoflurane and desflurane, faster emergence from anaesthesia is expected compared to traditional inhalation anaesthetics.

The purpose of this study was to compare the sevoflurane and desflurane in terms of hemodynamic, emergence and recovery characteristics in general anaesthesia.

\section{Materials And Methods}

The study was approved by the GRH ethical committee. Written informed consent were obtained from the patients.

\section{Selection of patients:}

The patients selected for this study were of ASA Risk I\&IIaged from 18 to 60 yearsundergoing elective surgical procedures under general anesthesia lasting for less than 3 hours but more than 1 hour duration. It was a prospective randomized controlled single blinded study. The patients exhibiting the following were excluded from the study:

- $\quad$ Significant cardiovascular, respiratory, hepatic, renal, neurologic, psychiatric or metabolic disease.

- $\quad$ Recent anesthetic exposure within previous seven days.

- $\quad$ History of allergic reaction to drugs.

- Potential susceptibility to malignant hyperthermia.

- $\quad$ Patient on chronic opioid analgesic or sedative treatment.

\section{Preoperative preparation:}

In the preoperative examination, all the patients were asked for any history of systemic illness like hypertension, diabetes, seizure disorder, bronchial asthma. History of any muscular dystrophies, neuromuscular disorders and family history of any malignant hyperthermia were noted. History of any allergic reactions to drugs and any chronic drug intake were noted. History of any previous surgeries was noted. Examination of the cardiovascular system and respiratory system were done. Assessment of the airway and the range of neck movements were done to rule out any difficult intubation. Apart from the routine blood investigations like haemoglobin, blood sugar, blood urea and serum creatinine, electrocardiogram and chest $\mathrm{x}$-ray were ordered in patients greater than 40 years of age.

Hypertensive patients were advised to continue the antihypertensives on the day of surgery. Diabetic patients were advised to skip the morning dose of insulin. The surgeons were instructed to post the diabetic case first in the list and to send the patient to the operating room with the fasting blood sugar and urine acetone values taken on the day of surgery.

On arrival to the preoperative room, all patients were premedicated with injection midazolam $0.05 \mathrm{mg} / \mathrm{kg}$ and injection glycopyrrolate $10 \mu \mathrm{g} / \mathrm{kg}$ intravenously 30 minutes prior to induction.

The patients were randomly allocated into two groups:

Group S- Sevoflurane 30 patients

Group D-Desflurane 30 patients

\section{Procedure details:}

After shifting the patient inside the operating room, pre induction monitors pulseoximetry, noninvasive blood pressure and electrocardiogram were connected. After securing the intravenous line and starting a crystalloid solution, all patients were induced with injection thiopentone sodium $5 \mathrm{mg} / \mathrm{kg}$, injection fentanyl $2 \mu \mathrm{g} / \mathrm{kg}$ and intubated with injection succinylcholine $1.5 \mathrm{mg} / \mathrm{kg}$. After intubation capnography was connected. Group D was maintained with 3\% desflurane and group S with $1 \%$ sevoflurane in $50 \%$ oxygen with $50 \%$ nitrous oxide. Neuromuscular blockade was maintained with injection vecuronium, initial bolus dose of $0.1 \mathrm{mg} / \mathrm{kg}$ was given. Ventilation was controlled to maintain end-tidal carbon dioxide between 35and40mmhg. Injection fentanyl $0.5 \mu \mathrm{g} / \mathrm{kg}$ was repeated every 30 minutes. Injection vecuronium $0.02 \mathrm{mg} / \mathrm{kg}$ was repeated every 30 minutes. Mean arterial pressure and heart rate were noted before induction and every 5 minutes after induction. If there is any increase in the mean arterial pressure and heart rate more than $20 \%$ of the preinduction values, an additional dose of injection fentanyl $1 \mu \mathrm{g} / \mathrm{kg}$ was given to maintain the hemodynamics. If there is any reduction in the mean arterial pressure more than $20 \%$ from the baseline value, it was treated with bolus of intravenous fluids and replacement of intraoperative blood loss. When the hemodynamics of the patient was unresponsive to the above measures, the patient was excluded from the study. Nitrous oxide and volatile anesthetic were discontinued after the last skin suture. Residual neuromuscular blockade was reversed with injection neostigmine $40 \mu \mathrm{g} / \mathrm{kg}$ and injection glycopyrrolate $10 \mu \mathrm{g} / \mathrm{kg}$ intravenously. Trachea was extubated when regular 
Comparison Of Hemodynamic, Emergence And Recovery Characteristics Of Sevoflurane With ..

spontaneous breathing pattern was re-established and when the patients were able to open their eyes on command.

The time of discontinuation of anesthetic agents were noted as time zero for all the subsequent measurements and recovery times were determined at 1-minute intervals to awakening.

\section{Parameters observed:}

$>$ Number of additional doses of fentanyl needed.

$>$ The time toFirst spontaneous motion, Response to painful pinch, Extubation, Recall of name, Hand grip, Achieve a PARS $>10$ (post anesthesia recovery score of Aldrete and Kroulik)

This PARS records vital signs with patients receiving 0-18 points that is 0-3 points for five physiological variables. One designated investigator administered all anesthesia; another assessed recovery.

\begin{tabular}{|c|c|c|}
\hline & Parameters & $\mathbf{S}$ \\
\hline \multicolumn{3}{|c|}{ Consciousness } \\
\hline & Easily arousable, alert & 3 \\
\hline \multicolumn{3}{|c|}{ Arousable, oriented, not alert } \\
\hline \multicolumn{3}{|c|}{ Arousable, not oriented } \\
\hline \multicolumn{3}{|c|}{ Not responding } \\
\hline \multicolumn{3}{|c|}{ Ventilation } \\
\hline & Normal & 2 \\
\hline & Not perfect, but requires no support & 1 \\
\hline & Airway requires support & 0 \\
\hline \multicolumn{3}{|c|}{ Circulation (mean, supine, sitting) } \\
\hline \multicolumn{3}{|c|}{ Arterial pressure difference } \\
\hline$<10 \%$ & & 2 \\
\hline $10-20$ & & 1 \\
\hline$>20 \%$ & & 0 \\
\hline \multicolumn{3}{|c|}{ Horizontal nystagmus } \\
\hline & Follow command, no nystagmus & 2 \\
\hline & Follow command, nystagmus & 1 \\
\hline & Fail to follow command & 0 \\
\hline \multicolumn{3}{|c|}{ Countdown test (backward from 10 to 0 ) } \\
\hline & Succeed right away & 2 \\
\hline & Succeed in 30 seconds & 1 \\
\hline & Fail in 30 seconds & 0 \\
\hline
\end{tabular}

\section{Statistical tools}

The information collected regarding all the selected cases were recorded in a Master Chart. Data analysis was done with the help of computer using Epidemiological Information Package (EPI 2010)developed by Centre for Disease Control, Atlanta.

Using this software range, frequencies, percentages, means, standard deviations, chi square and 'p' values were calculated. Kruskul Wallis chi-square test was used to test the significance of difference between quantitative variables and Yate's chi square test for qualitative variables. A 'p' value less than 0.05 is taken to denote significant relationship.

\section{Results And Discussion}

General anesthesia is popular among the surgeons, anaesthesiologists, and patients and still remains the mainstay of anesthesia in many centres. With the introduction of less soluble volatile anesthetics which promote early recovery and also maintains hemodynamics and provide amnesia makes general anesthesia the technique of choice for many patients.It is desirable to have a faster recovery from anesthesia. This study compared the hemodynamic, emergence and recovery characteristics of sevoflurane with desflurane in general anesthesia.

Table 1 shows the comparative parameters of the two groups. In this study, the sex composition of the two groups was identical without any difference. There was no significant difference in the ASA status of the two groups.

The time to spontaneous motion, eye opening, response to pain were shorter in the desflurane group. The time to extubation, recall of name, and hand grip were also shorter in the desflurane group compared to sevoflurane group. Post anesthesia recovery score of greater than 10 was achieved earlier in the desflurane 
Comparison Of Hemodynamic, Emergence And Recovery Characteristics Of Sevoflurane With ..

group. In the desflurane group, patient moved their limbs in a mean time of 4 minutes after the discontinuation of the anesthetics whereas it took a mean of 7.2minutes in the sevoflurane group.

The study by Nathanson et al. suggested that sevoflurane and desflurane provided similar intraoperative conditions during the maintenance period. Although early recovery was more rapid after desflurane, there was no difference in later recovery end-points.

'Randomised, double-blind study of Tarazi et al. showed that both sevoflurane and desflurane were acceptable inhalational anaesthetics for outpatient tubal ligation surgery.

In this study there was no significant difference in the recovery times between the two groups after 30 minutes.

Song et al. found that the late recovery profiles and incidences of postoperative side effects were similar after desflurane and sevoflurane. It was also showed that regardless of the duration of anaesthesia, elimination was faster and recovery was quicker for the inhaled anaesthetic desflurane than for the inhaled anaesthetic sevoflurane.

Both the desflurane and sevoflurane maintained the hemodynamics within $20 \%$ of the baseline values, but desflurane required more number of additional doses of fentanyl than sevoflurane.

In the desflurane group, hemodynamics could not be maintained with the additional doses of fentanyl in 3 patients and they were excluded from the study, were as in the sevoflurane group, only 1 patient was excluded from the study.

Hypotension was easily managed with fluids and blood replacement and none of the patients were excluded in both the groups.

\section{IV.Table}

Table 1: Comparison of characteristics of Sevoflurane with Desflurane in general anesthesia

\begin{tabular}{|c|c|c|c|c|c|c|}
\hline \multirow[t]{2}{*}{ S.No } & \multirow[t]{2}{*}{ Study Parameters } & \multicolumn{2}{|c|}{ Desflurane group } & \multicolumn{2}{|c|}{ Sevoflurane group } & \multirow[t]{2}{*}{ P value } \\
\hline & & Mean & SD & Mean & SD & \\
\hline 1 & (in yrs) & 39.8 & 10.8 & 39.4 & 10.4 & 0.7729 \\
\hline 2 & (in $\mathrm{Kg}$ ) & 52.5 & 3.0 & 52.2 & 3.1 & 0.7125 \\
\hline 3 & Duration of Surgery (in mins) & 112 & 19.4 & 110.2 & 18.4 & 0.5131 \\
\hline 4 & No. of addl doses of Fentanyl & 1.47 & 0.9 & 0.33 & 0.55 & 0.0001 \\
\hline \multicolumn{7}{|c|}{ Efficacy of drugs } \\
\hline 5 & $\begin{array}{l}\text { Time to spontaneous motion } \\
\text { (in mins) }\end{array}$ & 4 & 0.69 & 7.2 & 0.76 & 0.0001 \\
\hline 6 & $\begin{array}{l}\text { Time to response to pain (in } \\
\text { mins) }\end{array}$ & 5.37 & 0.85 & 8.57 & 0.86 & 0.0001 \\
\hline 7 & Time to extubation(in mins) & 6.53 & 0.82 & 10.4 & 1.07 & 0.0001 \\
\hline 8 & $\begin{array}{l}\text { Time to recall of name (in } \\
\text { mins) }\end{array}$ & 7.83 & 0.79 & 12.33 & 1.21 & 0.0001 \\
\hline 9 & Time to hand grip (in mins) & 9.37 & 0.89 & 14.27 & 1.34 & 0.0001 \\
\hline 10 & $\begin{array}{ll}\text { Time to achieve } & \text { PARS }> \\
10 \text { (in mins) } & \\
\end{array}$ & 10.47 & 0.86 & 16.63 & 1.47 & 0.0001 \\
\hline 11 & $\begin{array}{l}\text { Pulse rate }(/ \mathrm{min}) \\
\text { Baseline } \\
\text { Intraoperative }\end{array}$ & $\begin{array}{l}82.7 \\
82.7\end{array}$ & $\begin{array}{l}7.7 \\
7.2\end{array}$ & $\begin{array}{l}84.2 \\
80.1\end{array}$ & $\begin{array}{l}8.2 \\
8.1\end{array}$ & $\begin{array}{l}0.4092 \\
0.2704\end{array}$ \\
\hline 12 & $\begin{array}{l}\text { Mean arterial pressure } \\
\text { Baseline } \\
\text { Intraoperative }\end{array}$ & $\begin{array}{l}64.7 \\
65.11\end{array}$ & $\begin{array}{l}3.2 \\
3.27\end{array}$ & $\begin{array}{l}65.3 \\
63.69\end{array}$ & $\begin{array}{l}3 \\
2.96\end{array}$ & $\begin{array}{l}0.4097 \\
0.0685\end{array}$ \\
\hline
\end{tabular}

\section{Conclusion}

In conclusion, desflurane provides earlier emergence and recovery from anesthesia compared to sevoflurane. Both desflurane and sevoflurane maintained hemodynamic stability intraoperatively, but to maintain the hemodynamicsdesflurane needed more number of additional doses of fentanyl.

\section{References}

[1]. Eger II EI, Gong D, Koblin DD, et al: Effect of anesthetic duration on kinetic and recovery characteristics of desflurane vs. sevoflurane (plus compound A) in volunteers. AnesthAnalg 1998; 86:414-421.

[2]. McKay RE, Large MJC, Balea MC, McKay WR: Airway reflexes return more rapidly after desfluraneanesthesia than after sevoflurane anesthesia. AnesthAnalg 2005; 100:697-700.

[3]. Neumann MA, Weiskopf RB, Gong DH, et al: Changing from isoflurane to desflurane towards the end of anesthesia does not accelerate recovery in humans. Anesthesiology 1998; 88:914-921.

[4]. Nordmann GR, Read JA, Sale SM, et al: Emergence and recovery in children after desflurane and isoflurane anaesthesia: Effect of anaesthetic duration. Br J Anaesth 2006; 96:779-785.

[5]. Eger EI II, Bowland T, Ionescu P, et al. Recovery and kinetic characteristics of desflurane and sevoflurane in volunteers after 8-h exposure, including kinetics of degradationproducts. Anesthesiology 1997; 87: 517-26.

[6]. Juvin P, Vadam C, Malek L, et al. Postoperative recovery after desflurane, propofol, or isoflurane anesthesia among morbidly obese patients: a prospective, randomized study. AnesthAnalg 2000; 91: 714-9.

[7]. Song D, Joshi GP, White PF. Fast-track eligibility after ambulatory anesthesia: a comparison of desflurane, sevoflurane, and propofol. AnesthAnalg 1998; 86: 267-73. 
[8]. Beaussier M, Deriaz H, Abdelahim Z, et al. Comparative effects of desflurane and isoflurane on recovery after long lasting anaesthesia. Can J Anaesth 1998; 45: 429-34.

[9]. Nathanson MH, Fredman B, Smith I, White PF. Sevoflurane versus desflurane for outpatient anesthesia: a comparison of maintenance and recovery profiles. AnesthAnalg 1995; 81: 1186-90.

[10]. Smiley R, Ornstein E, Mateo RS, et al. Desflurane and isoflurane in surgical patients: comparison of emergence time. Anesthesiology 1991; 74: 425-8.

[11]. Chen X, Zhao M, White PF, et al. The recovery of cognitive function after general anesthesia in elderly patients: a comparison of desflurane and sevoflurane. AnesthAnalg 2001; 93: 1489-94.

[12]. Tarazi EM, Philip BK. A comparison of recovery after sevoflurane or desflurane in ambulatory anesthesia. $\mathrm{J}$ ClinAnesth 1998; 10: 272-7.

[13]. Faster wash-out and recovery for desflurane vs. sevoflurane in morbidly obese patients when no premedication is used Br J Anaesth September 1, 2007 99:353-358.

[14]. Emergence and Recovery Characteristics of Desflurane Versus Sevoflurane in Morbidly Obese Adult Surgical Patients: A Prospective, Randomized Study Anesth. Analg. December 1, 2004 99: 1848-1853.

[15]. Ghouri AF, Matthew B, White PF. Recovery profiles after desflurane-nitrous oxide versus isoflurane-nitrous oxide in outpatients. Anesthesiology 1991;74: 419-24.

[16]. Graham SG, Aitkenhead AR. A comparison between propofol and desflurane anaesthesia for minor gynaecological laparoscopic surgery. Anaesthesia 1993; 48: 471-5.

[17]. Dexter F, Tinker JH. Comparison between desflurane and isoflurane or propofol on time to following commands and time to discharge. A metaanalysis. Anesthesiology 1995;83:77 - 82.

[18]. Tang J, White PF, Wender RH, et al. Fast-track office-based anesthesia: a comparison of propofol versus desflurane with antiemetic prophylaxis in spontaneously breathing patients. AnesthAnalg 2001;92:95-9.

[19]. Meta-analysis of trials comparing postoperative recovery after anesthesia with sevoflurane or desflurane Am J Health Syst Pharm January 1,2005 62:63-68.

[20]. Earl M. Strum, Janos Szenohradszki, MD, PhD, et al. Emergence and Recovery Characteristics of Desflurane Versus Sevoflurane in Morbidly Obese Adult Surgical Patients: A Prospective, Randomized Study. Anesth\&Analg December 2004 vol.99 no.6 18481853 .

[21]. Smith I, Taylor E, White PF. Comparison of tracheal extubation in patients deeply anesthetized with desflurane or isoflurane. AnesthAnalg 1994; 79:642-5

[22]. Naidu-Sjösvärd K, Sjöberg F, Gupta A. Anesthesia for video arthroscopy of the knee: a comparison between desflurane and sevoflurane. ActaAnaesthesiolScand 1998; 42: 464-71.

[23]. Grundman U, Silomon M, Bach F, Becker S, Bauer M, Larsen, Kleinschmidt S. Recovery profile and side effects of remifentanilbased anaesthesia with desflurane or propofol for laparoscopic cholecystectomy. ActaAnaesthesiolScand 2001; 45: 320-326.

[24]. Bennett JA, Mahadeviah A, Stewart J, Lingaraju N, Keykhah MM: Desflurane controls the hemodynamic response to surgical stimulation more rapidly than isoflurane. J ClinAnesth 1995; 7: 288-291.

[25]. Loop T, Priebe HJ. Recovery after anesthesia with remifentanil combined with propofol, desflurane, or sevoflurane for otorhinolaryngeal surgery. AnesthAnalg 2000; Jul; 91 (1): 123-129.

[26]. Larsen B, Seitz A, Larsen R. Recovery of cognitive function after remifentanil-propofolanesthesia: a comparison with desflurane and sevoflurane anesthesia. AnesthAnalg 2000; Jan; 90 (1): 168-174. 